\title{
Dissecting the role of putative CD8 I binding regions of E2 in mediating HCV entry: Putative CD8 I binding region I is not involved in CD8 I binding
}

\author{
Katharina B Rothwangl1 ${ }^{1}$, Balaji Manicassamy ${ }^{1,3}$, Susan L Uprichard ${ }^{1,2}$ and \\ Lijun Rong*1
}

Address: ${ }^{1}$ Department of Microbiology and Immunology, College of Medicine, University of Illinois at Chicago, Chicago, IL 60612, USA, 2Department of Medicine, College of Medicine, University of Illinois at Chicago, Chicago, IL 60612, USA and ${ }^{3}$ Mount Sinai School of Medicine, 1 Gustave L. Levy Place, Box 1124 New York, NY 10029, USA

Email: Katharina B Rothwangl - Katharin@uic.edu; Balaji Manicassamy - Balaji.manicassamy@mssm.edu; Susan L Uprichard - Sluprich@uic.edu; Lijun Rons* - lijun@uic.edu

* Corresponding author

Published: 20 March 2008

Virology Journal 2008, 5:46 doi:10.1186/1743-422X-5-46

This article is available from: http://www.virologyj.com/content/5/I/46

(C) 2008 Rothwangl et al; licensee BioMed Central Ltd.

This is an Open Access article distributed under the terms of the Creative Commons Attribution License (http://creativecommons.org/licenses/by/2.0), which permits unrestricted use, distribution, and reproduction in any medium, provided the original work is properly cited.
Received: 24 December 2007

Accepted: 20 March 2008

\begin{abstract}
Background: Hepatitis $\mathrm{C}$ virus (HCV) encodes two transmembrane glycoproteins $\mathrm{EI}$ and $\mathrm{E2}$ which form a heterodimer. EI is believed to mediate fusion while E2 has been shown to bind cellular receptors including CD8I. In this study, alanine substitutions in E2 were generated within putative CD8I binding regions to define residues critical for viral entry. The effect of each mutation was tested by challenging susceptible cell lines with mutant HCV EIE2 pseudotyped viruses generated using a lentiviral system ( $\mathrm{HCV}_{\mathrm{PP}}$ ). In addition to assaying infectivity, producer cell expression and $\mathrm{HCV}_{\mathrm{PP}}$ incorporation of $\mathrm{HCV}$ EI and E2 proteins, CD8I binding profiles, and EIE2 association of mutants were examined.

Results: Based on these characteristics, mutants either displayed wt characteristics (high infectivity $[\geq$ $50 \%$ of wt $\mathrm{HCV}_{\mathrm{PP}}$ ], $\mathrm{CD} 8 \mathrm{I}$ binding, EIE2 expression, association, and incorporation into viral particles and proper conformation) or segregated into 4 distinct low infectivity $(\leq 50 \%$ of wt $\mathrm{HCV}$ PP) mutant phenotypes: (I) CD8I binding deficient (despite wt EIE2 expression, incorporation and association and proper conformation); (II) CD8I binding competent, but lack of EI detection on the viral particle, (despite adequate EIE2 expression in producer cell lysates and proper conformation); (III) CD8I binding competent, with adequate EIE2 expression, incorporation, association, and proper E2 conformation (i.e. no defect identified to explain the reduced infectivity observed); (IV) CD8I binding deficient due to disruption of E2 mutant protein conformation.

Conclusion: Although most alanine substitutions within the putative CD8I binding region I (amino acids 474-492) displayed greatly reduced HCVPP infectivity, they retained soluble CD8I binding, proper E2 conformation, EIE2 association and incorporation into $\mathrm{HCV}_{\mathrm{PP}}$ suggesting that region I of E2 does not mediate binding to CD8I. In contrast, conformationally correct E2 mutants (Y527 and W529) within the second putative CD8I binding region (amino acids 522-55I) disrupted binding of E2 to CD8I-GST, suggesting that region 2 is critical to CD8I binding. Likewise, all conformationally intact mutants within the third putative CD8I binding region (amino acids 6I2-6I9), except L6I5A, were important for E2 binding to CD8I-GST. This region is highly conserved across genotypes, underlining its importance in mediating viral entry.
\end{abstract}




\section{Background}

Hepatitis $\mathrm{C}$ virus (HCV) is a primary causative agent of chronic hepatitis. It is a positive-strand RNA virus in the family Flaviviridae that encodes a polyprotein of approximately 3,000 amino acids. This polyprotein is cleaved into ten viral proteins including two transmembrane envelope glycoproteins, E1 and E2, which are heavily Nglycosylated in their N-terminal ectodomains. Like other Flaviviruses, the interactions of the E1 and E2 glycoproteins with cell surface receptors mediate HCV entry via receptor mediated endocytosis [1]. It is believed that E1 mediates fusion of the membranes and E2 binds the cellular receptors, but it is not clear whether the fusion peptide resides in E1 or E2 [2].

Several cellular surface molecules have been implicated in HCV entry, including: CD81 [3-6], scavenger receptor class B type I (SR-BI) [7-9], the low-density lipoprotein receptor (LDLR) [10,11], Claudin-1,6 and 9 [12-14], dendritic-cell-specific intercellular adhesion molecule 3-grabbing nonintegrin (DC-SIGN) [15-17] and Liver/lymph node-specific intercellular adhesion molecule-3-grabbing integrin (L-SIGN) $[18,19]$. While L-SIGN and DC-SIGN are not expressed on hepatocytes, it is believed that dendritic cells expressing these molecules facilitate persistent infection by capturing and delivering the virus to the liver $[18,19]$. SR-BI is a multiligand receptor that binds several lipoproteins, including HDL, LDL and VLDL. It is primarily expressed in the liver and facilitates the uptake of lipids [20,21]. In infected patient's sera, HCV is found associated with LDL and VLDL, leading to the hypothesis that HCV may be "hitching a ride" with the lipoproteins to infect susceptible cells via lipoprotein receptors.

The role and requirement for CD81 in HCV entry has been thoroughly characterized and documented [3$6,22,23]$. CD81 is a non-glycosylated, membrane bound protein characterized by four transmembrane domains and a small (SEL) and large (LEL) extracellular loop [2428]. This protein is present on virtually all nucleated cells. Experiments establishing a definitive role for CD81 in HCV infection have been achieved using the retroviral pseudoparticle (HCVpp) and the recently developed in vitro HCV infectious clone systems [29-32]. The LEL of CD81 has been identified as the binding region of HCV E2 and critical amino acids for maintaining this interaction have been determined [33,34]. On the other hand, while several putative CD81 binding regions of HCV E2 have been identified, the critical amino acids of the E2 protein that bind CD81 are not well defined. The first proposed region spans the second hypervariable domain, extending from amino acid 474-492 [35-39]. The second region identified spans position 522-551 [35-39] and the third region is between amino acids 612-619 [35,36].
Notably, the amino acid composition of these regions varies significantly between individual viral genomes because HCV undergoes rapid genetic change requiring classification into multiple, naturally occurring genotypes. Amino acid sequences between these different genotypes vary approximately $30 \%$ and even within a single genotype, differences can range from 5-10\% [40]. Thus, within HCV-infected individuals, the virus exists as a quasispecies. This is presumably due to both the random, high error rate of viral RNA polymerase as well as immune pressure [41]. Because the E2 glycoprotein varies so much, identifying conserved residues within these putative regions that are critical for maintaining the interaction between CD81 and HCV, might provide important insight not only for elucidating the molecular mechanism of viral entry, but also for developing entry inhibitors as a novel therapeutic option.

In this study, to define residues critical for viral entry, individual alanine substitutions in the three putative CD81 binding regions were generated via site-directed mutagenesis. The strategy was to target residues that are highly conserved across several strains of $\mathrm{HCV}$, as retention of specific residues across genetically diverse genotypes strongly implicates those residues as being important for the interaction between HCV E2 and CD81. Although the hypervariable region II (HVR II) extends into the first putative CD81 binding region targeted (residues 474482), residues Y474 and D481 are very highly conserved and were therefore also targeted in this study. Susceptible cell lines were challenged with HCV E1E2 pseudovirus (HCVpp) containing the individual mutations to determine the effect of each mutation on HCVpp infectivity. Additionally, producer cell expression and HCVpp incorporation of HCV E1 and E2 proteins, CD81 binding profiles, conformation and E1E2 association of mutants were also examined.

\section{Results}

Identification of highly conserved, charged, hydrophobic residues within the putative $C D 8$ I binding regions of E2

Three putative CD81 interaction sites on HCV E2 have been previously identified; region 1, 474-492 [35-39]; region 2, 522-551 [35-39]; and region 3, 612-619 $[35,36]$. Remarkably, although E2 is subject to strong immune selective pressure in vivo, sequence alignment indicates that there is a high degree of sequence conservation within these three regions, consistent with the idea of these regions having functional importance. Among the three putative CD81-binding regions, region 3 (residues 612-619) is the most conserved, while region 1 (residues 474-492) has the greatest sequence variability, which is expected as the second hypervariable region (HVR II) extends into positions 474-482 (Fig. 1). Although within the HVR II, amino acids Y474 and D481 are still very 


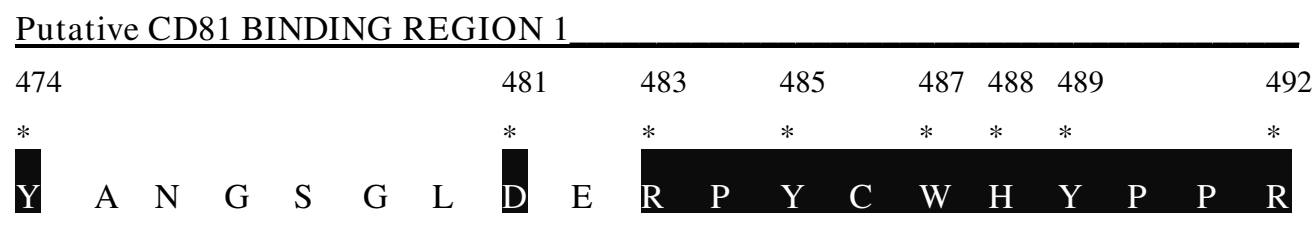

\section{Putative CD81 BINDING REGION 2}

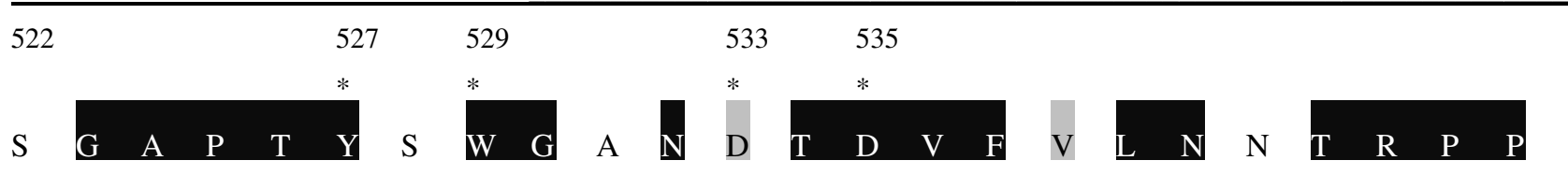
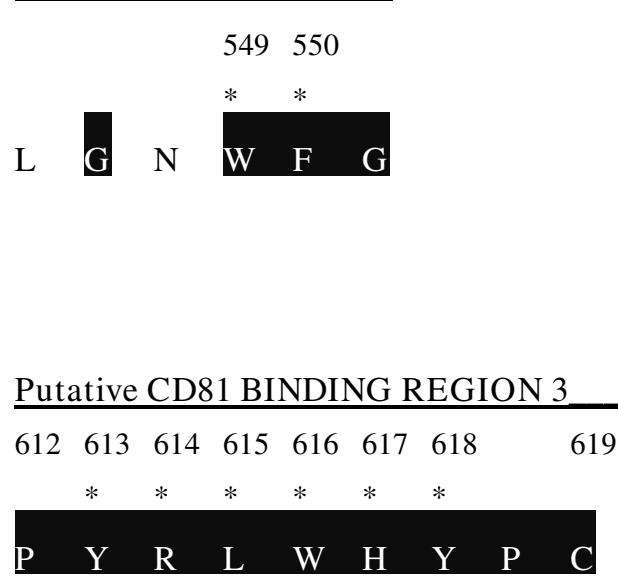

Figure I

Conserved residues within the putative CD8 I binding domains of E2. HCV strains from the Los Alamos HCV sequence database were aligned. Three regions previously implicated in CD8I binding were analyzed. Amino acids are numbered relative to the AUG start codon of the H77 strain shown and used in this study. The hyperconserved (black rectangles) targeted (asterisk) residues for alanine substitution are indicated.

highly conserved and were therefore targeted. Being interested in identifying amino acids that directly mediate HCV E2 protein-protein interactions with CD81, we decided to focus in large part on charged, hydrophobic residues conserved in these regions.

\section{Effect of E2 alanine substitutions on the infectivity of HCVpp}

To identify which of the charged, conserved amino acids in the three putative CD81 interaction sites of E2 are critical for infectivity, a panel of alanine substitutions was generated within the context of H77 E2 (Fig. 1 and Fig. 2). The substitutions are numbered based on their position within the polyprotein of the $\mathrm{H} 77$ clone and use the one letter amino acid code to denote the amino acid present at the site prior to alanine substitution. After sequence confirmation of the alanine substitutions, HCVpp infectivity of permissive Huh7 and Hep3B cells was assessed by inoculating cells with HIV virions pseudotyped with either wt E1E2 or the mutant E1E2 glycoproteins (Fig. 2). While Huh7 cells support robust HCV infection in vitro [29-32] and are thus obviously a relevant cell lines for this analysis, confirmatory screening was also performed in Hep3B cells, which have been shown to be permissive for HCVpp entry. Infectivity was determined as a measure of luciferase activity. In these experiments, VSVG/HIV virions were used as a positive control. As expected, infection of the cells by VSVG/HIV virus leads to a high level of luciferase activity ( $\left.10^{7} \mathrm{RLU}\right)$ (Fig. 2). Infection of the target cells by wt HCV E1E2/HIV virus resulted in luciferase lev- 
A
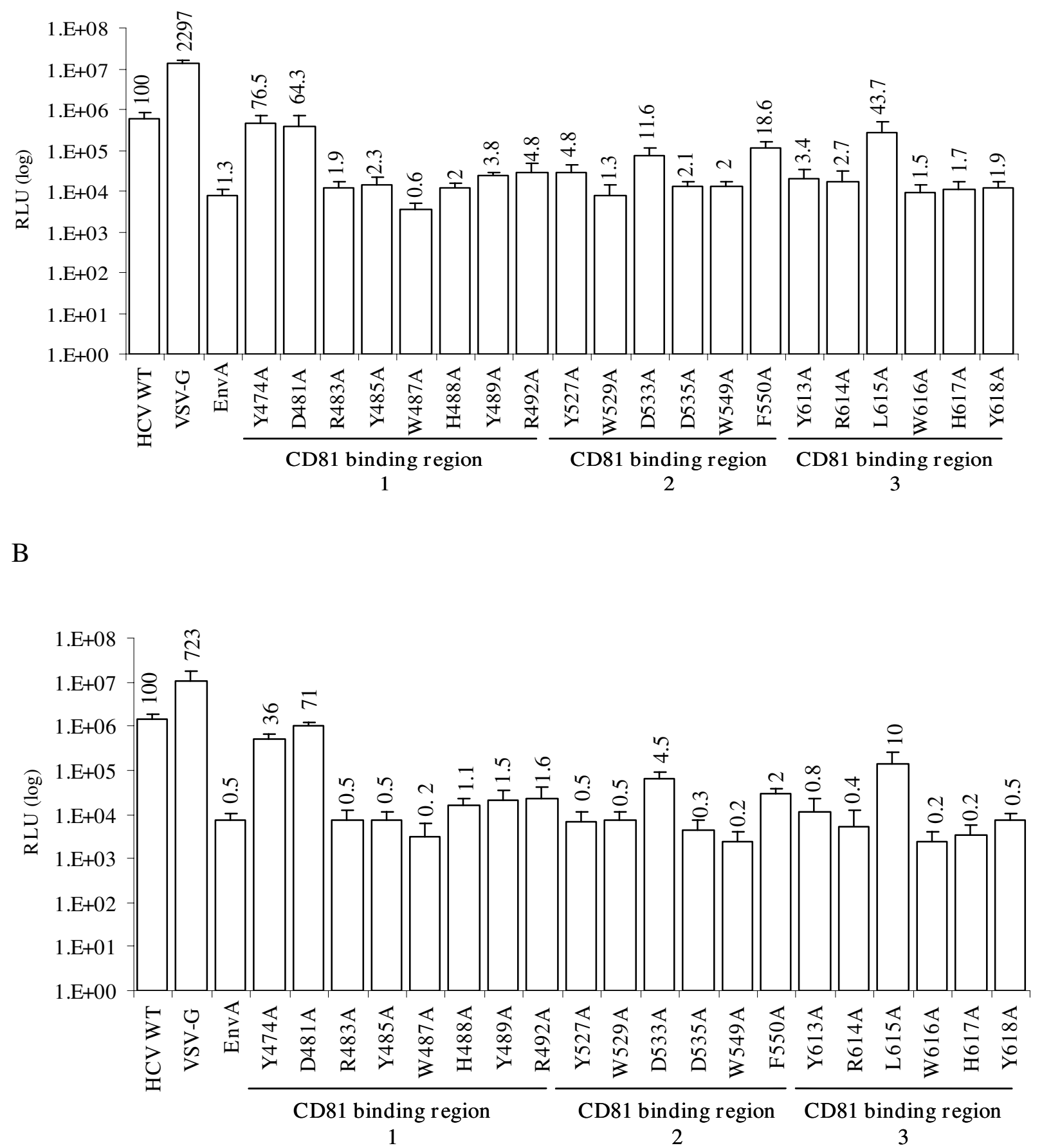

Figure 2

Alanine substitutions within putative CD8 I binding regions dramatically affect HCVpp entry. 293T cells were cotransfected with the HIV-luc packaging vector along with HCV EIE2 mutant expression plasmids. HCVPP was harvested at $24 \mathrm{~h}$ post-transfection and used to infect susceptible cell lines (A) Huh7 and (B) Hep3B. Infectivity was measured $72 \mathrm{~h}$ pi using a luciferase reporter assay. Infectivity of each mutant is expressed as a percentage of the infectivity observed for the wild-type (wt) H77 HCV EIE2. Values shown are the mean and standard error for a minimum of three assays. 
els at least $2 \log$ above a negative control, EnvA/HIV [42]. In the first putative CD81 binding region, two mutations at positions 474 and 481 retained a significant degree of infectivity relative to that of wt HCVpp E1E2 control. D481A demonstrated quantitatively similar infectivity in both Huh7 (Fig 2A) and Hep3B (Fig. 2B) cells (64\% and $71 \%$ respectively), compared to wt. While mutant Y474A retained a higher percent infectivity in the Huh7 cells (76\%) compared to Hep3B cells (36\%), in both cell lines Y474A exhibited one of the highest levels of infectivity among the mutants tested. In contrast to these 2 mutants, the remaining alanine substitutions within the first putative CD 81 binding region reduced infectivity to $5 \%$ or less of wt in both Huh7 and Hep3B cells. In the second putative CD81 binding region, alanine substitution of conserved residues severely decreased infectivity in both cell lines. While the predominant phenotype of mutations in the putative CD81 binding region 2 was ablation of infection, the D533A and F550A mutants did retain some detectable level of infectivity in Huh7 cells, 12 and 19\% respectively. However this minimal level of infection was not detected in the Hep3B cell assay, confirming the severity of the infectivity defect associated with changes in these residues. Finally, in the third putative CD81 binding region, all mutations, with the exception of L615A, impaired infectivity below $4 \%$. As seen with the Y474A mutation in region 1 , the exact amount of infectivity exhibited by L615A varied between cell lines with $44 \%$ of wt levels observed in Huh7 compared to $10 \%$ of wt levels observed in Нер3В cells; however, the trend of reduced infectivity was consistent.

Notably, the infectivity trend observed for all the mutants was the same in both Huh7 and Hep3B cells, indicating the importance of these specific conserved HCV E2 residues for HCV entry in both cell types. Interestingly however, with the exception of $\mathrm{D} 481 \mathrm{~A}$, all mutations maintained a higher level of infection in Huh7 cells compared to Hep3B, even though the baseline of HCV wt infectivity was slightly higher in Hep3B. This was particularly evident for the Y474A and L615A mutations noted above which exhibited $76 \%$ and $44 \%$ infectivity respectively in Huh7 cells compared to $36 \%$ and $10 \%$ infectivity in Hep3B cells. It remains to be determined if these quantitative differences are informative.

\section{Expression and incorporation of HCV EIE2 mutants}

To confirm adequate expression of the various $\mathrm{E} 2$ alanine substitutions, mutant E2 protein levels in the 293T producer cell lysates transiently transfected with HIV-luc backbone and the HCV E1E2 glycoprotein plasmids were examined by Western Blot analysis. Actin levels were used as a control for protein loading. When probed with antiE2 antibody, a band of $\sim 70 \mathrm{kDa}$ was detected in the cell lysate of wt and all mutant glycoprotein transfected cells, corresponding to the size of the HCV E2 protein (Fig. 3A). Overall, cell lysate levels of E2 were reduced for the mutants in the putative CD81 binding regions 2 and 3, compared to region 1 (Fig. 3A). To determine if this reduced intracellular expression has an effect on E1E2 incorporation onto the viral particle, virions were pelleted through a $20 \%$ sucrose cushion and examined by Western Blot, probing for p24 capsid levels to control for pseudovirus particle loading. E2 extracted from the viral particle displayed a diffuse migration pattern with at least three distinct bands, most likely due to extensive N-linked glycosylation (Fig. 3B)[43]. These various forms of E2 were incorporated into particles regardless of the specific E2 mutation present and independent of the intracellular accumulation levels of the protein (Fig. 3A). Hence, the lower intracellular E2 levels detected for the mutants in regions 2 and 3 were not reflected in the amount of E2 incorporated into the viral particle. Levels of E1 detected on the various mutant viral particles however, varied greatly. Most dramatically, although E2 incorporation was not impaired, E1 was not detected in W487A or W549A mutant viral particles. This could either be due to the loss of the monoclonal antibody epitope the Western Blot was probed with or due to a lack of incorporation onto the viral particle. Based on these two E2 mutations coming down in the conformational antibody immunoprecipitation (Fig. 4B), we suspect E1 is present on HCVpp since both E1 and E2 need to be present for proper folding [44]. In any case, the level of E1 detected on the different mutant viral particles did not correlate with infectivity levels or correspond to a specific binding region. At the positions where greater levels of E1 were detected, the bands appeared as a couplet.

\section{Characterization of E2 mutant CD8 I binding}

Although E1 and mutant E2 glycoproteins were detected on viral particles except W487A and W549A, infectivity was nonetheless severely impaired in most of them. To establish if this was due to disruption of CD81 binding, as predicted based on the previous identification of these regions as putative CD81 binding domains, the binding of the mutants to recombinant soluble CD81-LEL [4] was assayed. In these experiments, binding of HCV E1E2 proteins to a purified GST tag was used as a control. Unexpectedly, twelve of the twenty mutants bound soluble CD81 at levels similar to wt, including all the mutations in the putative CD81 binding region 1 (Y474A, D481A, R483A, Y485A, W487A, H488A, Y489A, and R492A) suggesting that this region is not directly involved in binding CD81 (Fig. 4A). The fact that HCVpp infectivity was severely reduced in response to all region 1 mutants except Y474A and D481A, therefore suggests that this region likely plays another role in the viral entry process. On the other hand, while several of the mutations in regions 2 and 3 (D533A, W549A, F550A, and L615A) 
A.

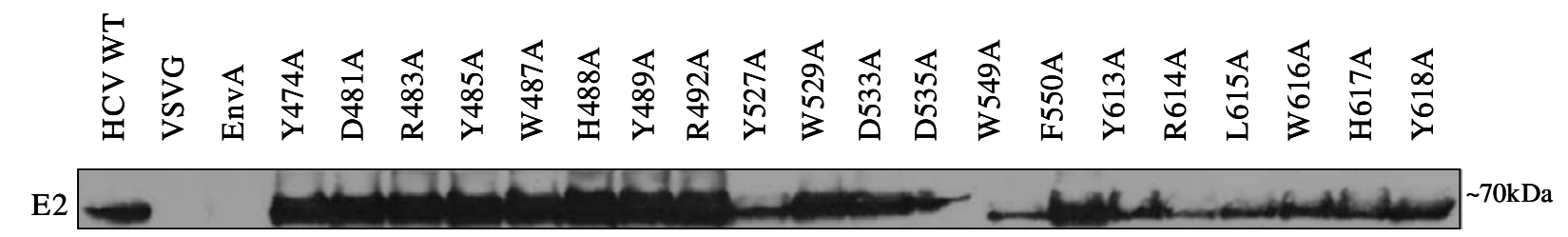

actin

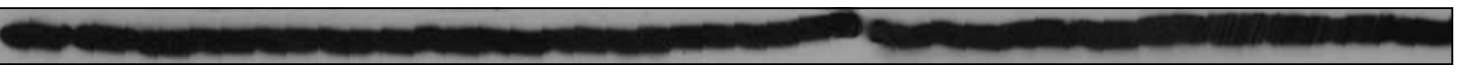

B.

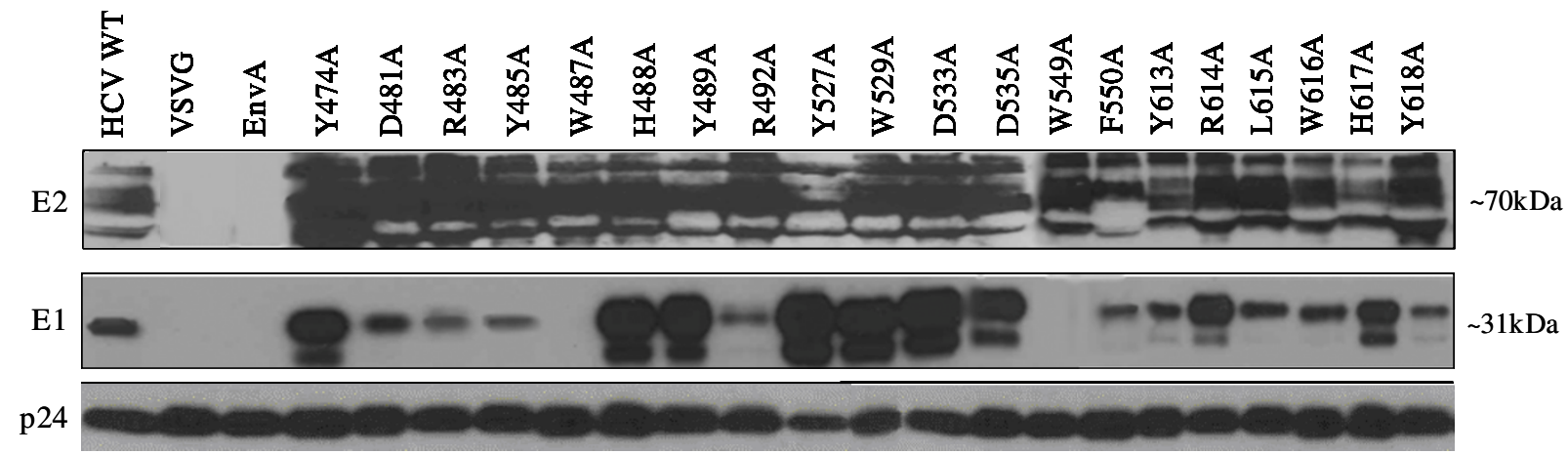

Figure 3

Expression and incorporation of HCV EIE2 glycoproteins in producer cell lysate and HCVpp. (A) 293T HCV PP producer cells were lysed and analyzed by Western Blot analysis using anti $(\alpha)$-E2 and $(\alpha)$-actin antibodies. Image is a composite. (B) Incorporation of HCV glycoproteins into HCVPP was determined by pelleting the virus through a $20 \%$ sucrose cushion followed by Western Blot analysis. HCV glycoproteins were identified with $(\alpha)$-E2 and $(\alpha)$-EI antibodies. Detection of the HIV P24 capsid protein with an anti-HIV p24 antibody was performed as a loading control. Image is a composite.

retained the ability to bind CD81, indicating that these specific residues are also not directly involved in the E2 and CD81 interaction, eight of the substitution mutants in these domains did not bind CD81 (Fig. 4A), consistent with the involvement of regions 2 and 3 in CD81 binding. Specifically, mutants W529A, D535A, Y613A, R614A, W616A and H617A did not bind soluble CD81 at all, and two mutants, Y527A and Y618A, exhibited dramatically reduced interaction with CD81.

To confirm that loss of CD81 binding was not due to a more general disruption of E2 structure in this region of the protein, we performed immunoprecipitation of CD81 binding deficient mutants with an antibody that recognizes a conformational epitope within the putative CD81 binding regions 2 and 3 [45]. Wt and the CD81 binding competent D533A mutants as well as W487A and W549A, for which we did not detect E1 on the viral particle, were captured with the conformational antibody, consistent with proper folding. While the Y527A, W529A, Y613A, H617A and Y618A E2 mutants were all deficient for CD81 binding, they too were recognized by the conformationdependent antibody, indicating their conformation remained in tact. This strongly implicates these five residues as being critical for CD81 binding. In contrast, three of the mutations that did not bind CD81, (D535A, R614A and W616A) did not come down in the immunoprecipitation assay, suggesting mutations in these residues might have resulted in more global changes in E2 conformation. While loss of AR3A binding could also be due to changes in specific amino acids within the AR3A epitope, for the moment we consider these mutants as uninformative because the overall structure of the protein might be compromised. 
A.

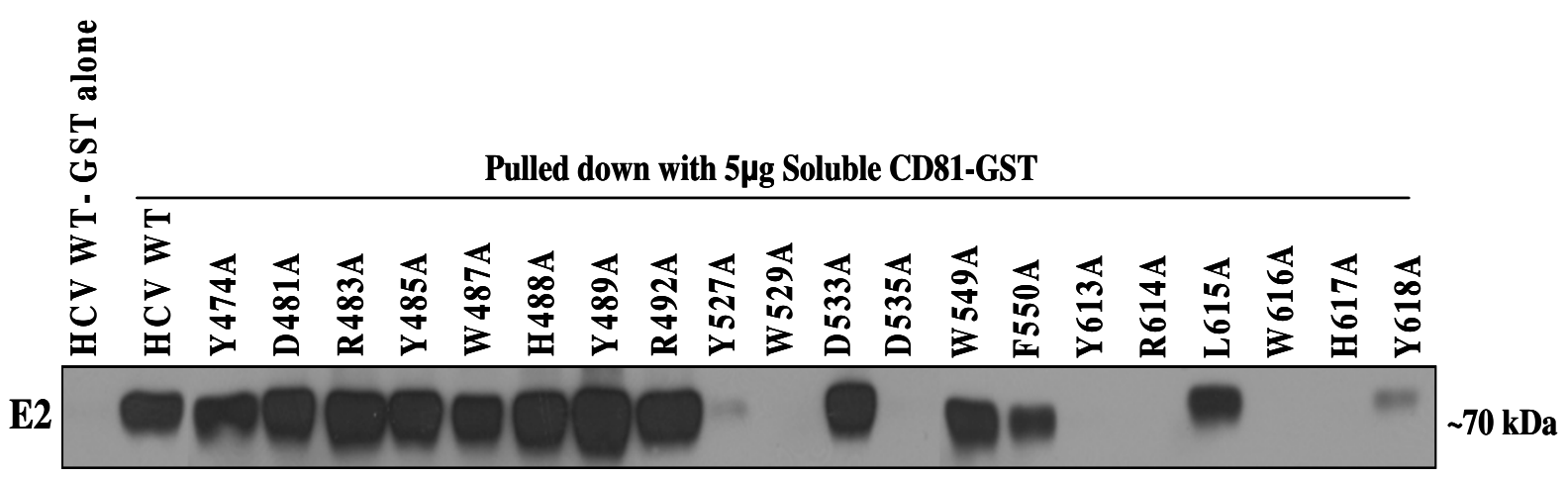

Gst tag $\longrightarrow \sim 26 \mathrm{kDa}$

B.

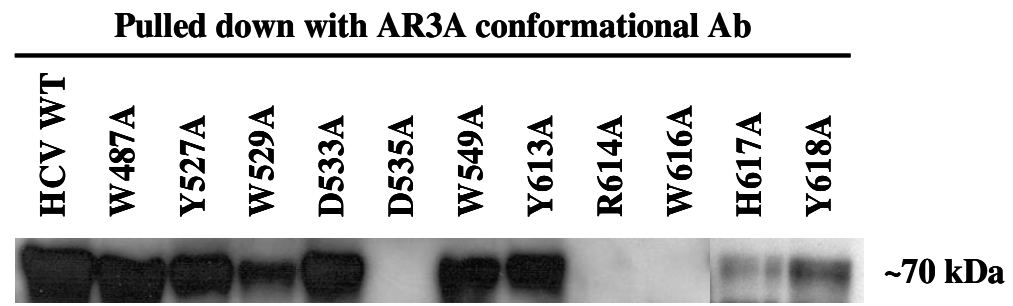

\section{Figure 4}

Binding of mutant HCV E IE2 glycoproteins to soluble CD8I. (A) 293T cells transfected with HCV EIE2 wt or mutant expression vectors were lysed $24 \mathrm{~h}$ post-transfection. Cleared cell lysate was incubated with soluble CD8I-GST fusion protein. Binding to CD8I was determined by Western Blot analysis of E2 and the GST tag. As a negative control, GST protein without soluble CD8I was incubated with HCV wt. Image is a composite. (B) 293T cells transfected with HCV EIE2 wt or specific mutant expression vectors were lysed $24 \mathrm{~h}$ post-transfection. Cleared cell lysate was incubated with $A R 3 A(C I)$ conformational antibody to assess conformation of mutations. Immunoprecipitated proteins were detected by subsequent Western Blot analysis of E2. Image is a composite.

\section{Analysis of EI and E2 association}

Having identified several E2 mutations that exhibit severely reduced infectivity while retaining the ability to bind CD81, we next investigated whether any of the alanine substitutions in E2 disrupted E1E2 association. It is known that E1 and E2 must properly dimerize in order to mediate HCV infectivity [2,43,46-49]. This is a relevant consideration for these mutations as E2 dimerization domains have been mapped to the transmembrane domains, a WHY motif at positions 487-489, amino acids 415-500 as well as amino acids L675, S678, L689 and L692 [48,50-53]. For this analysis, 293T cells were transiently transfected with the HCV glycoprotein constructs then lysed $48 \mathrm{~h}$ later. E2 protein was pulled down with polyclonal HCV E2 antibody and immunocomplexes were analyzed by Western Blot for the presence of E1 using a monoclonal antibody. To control for E2 antibody specificity, 293T cells were also transfected with E1 alone. For several mutants, most notably W549A, F550A and R614A, a greater amount of E2 was detected compared to wt (Fig. 5). Notably however, despite varying levels of E2 pulled down, E1 was detected in association with all the E2 mutants.

\section{Discussion}

In this study we investigated the role of conserved, charged amino acid residues in three putative CD81 binding regions of HCV E2: region 1: amino acid 474-492, region 2: position 522-551 and putative region 3: amino acids 612-619 [35-39]. The 20 alanine substitution mutants characterized in this study can be classified into those displaying wt characteristics (high infectivity $[\geq$ $50 \%$ of wt HCVpp], CD81 binding, E1E2 expression, association, and incorporation into viral particles) or seg- 
regated into 4 distinct low infectivity $(\leq 50 \%$ of wt HCVpp) mutant phenotypes: (I) CD81 binding deficient (despite wt E1E2 expression, incorporation and association and proper conformation); (II) CD81 binding competent, but cannot detect $\mathrm{E} 1$ on the viral particle (despite adequate E1E2 expression in producer cell lysates and proper conformation); (III) CD81 binding competent, with adequate E1E2 expression, incorporation, association, and conformation (i.e. no defect identified to explain the reduced infectivity observed); (IV) uninformative mutants with potential disruptions in protein conformation (see Table 1 ). With only 2 mutations (W487A and W549A) appearing to result in pseudotyped particles lacking E1, most infectivity deficient alanine substitutions fell into the first or third group (i.e. CD81 binding defective or unexplained defect, respectively).

Overall, our results support the notion that putative CD81 binding regions 2 and 3 are involved in CD81 binding as 5 class I mutants (Y527A, W529A, Y613A, H617A and Y618A) (see Fig. 4) demonstrate a defect in CD81 binding while maintaining proper conformation. Eleven of the twenty mutations are defective for infection (see Fig. 2), independent of CD81 binding and conformation (classes II and III) (see Table 1), suggesting that these E2 residues are involved in other essential aspects of HCV entry. All infectivity deficient mutations within the first putative CD81 binding region, with the exception of W487A, belong to the CD81 binding competent group III mutants for which we do not know why they are defective (see Fig. 2 and 4), indicating that this region, although important for HCV entry, is not directly involved in CD81 binding.
In contrast, the majority of infectivity defective substitutions in the putative CD81 binding regions 2 (Y527A, W529A and D535A) and 3 (Y613A, R614A, W616A, H617A and Y618A) demonstrate little to no CD81 binding, consistent with these regions being involved in CD81 binding. Whereas D535A, R614A and W616A all displayed a disrupted AR3A epitope in this region, indicative of more global structural aberrances Y527A, W529A, Y613A, H617A and Y618A have intact conformation and still are unable to bind CD81, defining these residues as critical for the HCV E2 and CD81 interaction. In addition, both regions 2 and 3 contain at least one group III mutation that reduces infectivity, but maintains the ability to bind CD81 (e.g. D533A, F550A, and L615A). Thus, it is likely that regions 2 and 3 are also involved in other aspects of viral entry. Notably, this is in agreement with a report by Owsianka et al. [54], which examined some of the same mutants in this region. While the degree of infectivity or CD81 binding quantified for the D533A and F550A mutants, respectively varied between the two studies, the phenotype of the mutants and conclusions drawn are qualitatively consistent

The first and third putative CD81 binding domains targeted, both contain a "WHY" motif. The first "WHY" motif (487-489) has been implicated in dimerization [52] and the second "WHY" motif (616-618) falls within region 600-620, which has been demonstrated to be involved in fusion [55]. Alanine substitution of any residues within either two of these motifs resulted in complete elimination of HCVpp infectivity. Consistent with a possible role of the region 1 "WHY" motif in proper E1E2 dimerization, Western Blot analysis of W487A HCVpp showed that substitution of tryptophan at position 487

\section{Cell lysate}

(no pull down)

Pull down with $5 \mu$ E 2 antibody

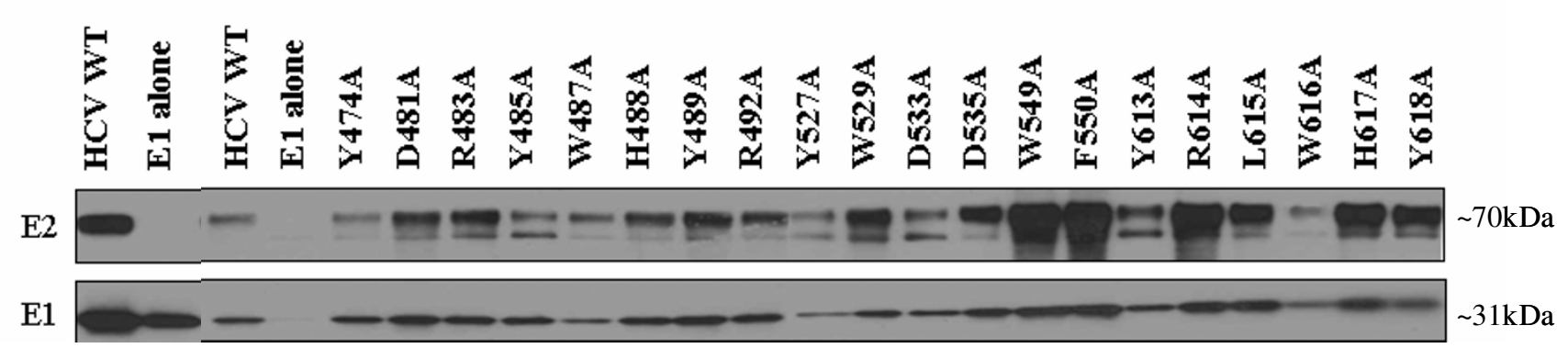

\section{Figure 5}

Determining association of EIE2 mutants. 293T cells were transfected with HCV EIE2 wt, mutant, or EI alone glycoprotein expression plasmids. Cells were lysed and cleared cell lysate was incubated with anti $(\alpha)$-E2 antibody. Immune complexes were separated by SDS-PAGE and analyzed by Western Blot for EI to determine if the E2 and EI glycoproteins had formed dimers. Image is a composite. 
Table I:

\begin{tabular}{|c|c|c|c|c|c|c|c|c|c|c|}
\hline \multirow[t]{2}{*}{$\mathrm{HCV}_{\mathrm{PP}}$} & \multirow[t]{2}{*}{ Infect. } & \multicolumn{2}{|c|}{ Infectivity (\%) } & \multirow{2}{*}{$\begin{array}{c}\text { Cellular Express. } \\
\text { E2 }\end{array}$} & \multicolumn{2}{|c|}{ HCVPP EIE2 Detection } & \multirow[t]{2}{*}{ EIE2 Assoc. } & \multirow[t]{2}{*}{ CD8I-GST Binding } & \multirow[t]{2}{*}{ Conform. } & \multirow[t]{2}{*}{ Group } \\
\hline & & Huh7 & Нер3В & & El & E2 & & & & \\
\hline WT & +++ & 100 & 100 & +++ & ++ & +++ & + & +++ & +++ & wt \\
\hline Y474A & ++ & 77 & 36 & +++ & +++ & ++++ & + & +++ & NA & wt\&III \\
\hline D48IA & +++ & 64 & 71 & +++ & + & ++++ & ++ & +++ & NA & wt \\
\hline $\mathrm{R} 483 \mathrm{~A}$ & - & 2 & 1 & +++ & + & ++++ & ++ & ++++ & good & III \\
\hline Y485A & - & 2 & 1 & +++ & + & ++++ & + & +++ & good & III \\
\hline W487A & - & I & 0 & +++ & - & ++++ & + & +++ & +++ & II \\
\hline $\mathrm{H} 488 \mathrm{~A}$ & - & 2 & 1 & +++ & +++ & ++++ & + & +++ & good & III \\
\hline Y489A & - & 4 & 2 & +++ & +++ & +++ & ++ & ++++ & good & III \\
\hline R492A & - & 5 & 2 & +++ & + & ++++ & + & +++ & NA & III \\
\hline Y527A & - & 5 & 1 & + & ++++ & + & + & - & +++ & 1 \\
\hline W529A & - & 1 & I & ++ & ++++ & ++++ & +++ & - & ++ & 1 \\
\hline D533A & - & 12 & 5 & ++ & ++++ & ++++ & + & +++ & +++ & III \\
\hline D535A & - & 2 & 0 & ++ & +++ & +++ & ++ & - & - & IV \\
\hline W549A & - & 2 & 0 & + & - & ++++ & ++++ & +++ & +++ & II \\
\hline F550A & - & 19 & 2 & ++ & + & +++ & ++++ & ++ & good & III \\
\hline Y6I3A & - & 3 & I & + & + & +++ & ++ & - & +++ & 1 \\
\hline R6I4A & - & 3 & 0 & + & ++ & ++++ & ++++ & - & - & IV \\
\hline L615A & + & 44 & 10 & + & + & ++++ & +++ & ++ & NA & III \\
\hline W6I6A & - & 2 & 0 & + & + & +++ & + & - & - & IV \\
\hline H6I7A & - & 2 & 0 & + & ++ & + & +++ & - & + & 1 \\
\hline Y618A & - & 2 & 1 & + & + & ++++ & +++ & $+/-$ & + & 1 \\
\hline
\end{tabular}

+ and - denote the properties of wt and mutants of HCV E2

"NA" indicates mutations not screened in this study and "good" indicates mutants screened in previous study [45]

resulted in an inability to detect the E1 epitope on HCVpp, despite the presence of E1 in producer cell lysate (see Fig. 3A). Although Lavillette et al. [55] observed a loss of both E1 and E2 glycoprotein incorporation into mutant W487A HCVpp particles, while we still detected E2 on HCVpp, our inability to detect E1 on W487A particles resulted in the classification of W487A as a group II mutant (i.e. a mutant exhibiting a defect in HCV glycoprotein incorporation), and is hence consistent with the previous report. In contrast, both H488A and Y489A mutants within region 1 did not appear to disrupt E1E2 interaction and were thus categorized as group III (i.e. no identifiable defect to explain loss of infectivity) (see Table 1).

Unlike the mutations within the region 1 "WHY" motif, CD81 binding was disrupted in all three alanine substitutions within the "WHY" motif of the third region (see Fig. 4). Mutation W616A however was not recognized in the AR3A immunoprecipitation assay, indicating that the structure of the CD81 binding epitope may have been disrupted. Therefore W616A was grouped as class IV. While lower amounts of both the H617A and Y618A mutants were captured by the AR3A antibody, suggesting that folding of these mutant proteins might be less efficient than $\mathrm{wt}$, there was a population of these mutant proteins which retained this conformational epitope and could thus be analyzed for CD81 binding ability. In contrast to the H488A and Y489A mutants within region 1 however, the
H617A and Y618A mutants in region 3 demonstrated reduced CD 81 binding classifying then as group I mutants and implicating them as being directly involved in E2 binding to CD81.

In conclusion, we have determined that the second and third putative CD81 binding regions are responsible for mediating E2 binding CD81. In the second region, residues Y527, W529 and D535 are critical for CD81 binding. The third putative CD81 binding region comprises a CD81 binding region, as all alanine substitutions, aside from L615A, are unable to interact with CD81. This region is conserved across genotypes, underlining its significance. Finally, we have determined that the first putative CD81 binding region is not a CD81 binding region, as all mutations bind CD81 at wt levels.

\section{Methods}

\section{Cell lines and antibodies}

293 T human embryonic kidney cells were maintained in Dulbecco's modified Eagle's media (DMEM) supplemented with $10 \%$ fetal calf serum with penicillin, streptomycin. Huh7 and Hep3B cells were maintained in DMEM supplemented with $10 \%$ fetal calf serum, penicillin, streptomycin and supplemented with $5 \mathrm{ml}$ Hepes (1 M) (Gibco), and Nonessential amino acids (NEAA) (Gibco). The goat polyclonal antibody against hepatitis $\mathrm{C}$ virus (HCV) E2 and the monoclonal mouse antibody for E1 
glycoproteins (GP) (genotype 1a) were obtained through ViroStat. The mouse anti-HIV p24 monoclonal antibody was obtained from the National Institutes of Health AIDS Research and Reference Reagent Program. Polyclonal rabbit glutathione-S-transferase (GST) antibody was obtained from NeoMarkers. The conformational anti-E2 AR3A antibody was provided by Dennis Burton, PhD from The Scripps Research Institute.

\section{Mutagenesis of the HCV E2 glycoprotein gene}

The cDNA clone containing E1E2 from genotype 1a strain H77 in pCB6, was kindly provided by Charles Rice, PhD (Rockefeller University). All alanine substitution mutations of the HCV E2 glycoprotein were generated by sitedirected mutagenesis with the Stratagene Quick-Change mutagenesis kit according to the supplier's protocols. All mutations were confirmed by DNA sequencing.

\section{Pseudotyping}

Pseudotyped viruses were produced by cotransfecting DNA encoding wild-type (wt) or mutant glycoproteins with the Env-deficient HIV vector carrying a luciferase reporter gene ( $\mathrm{pNL4}$-3-Luc-R-E- ) into $293 \mathrm{~T}$ producer cells. One microgram of the wt or mutant glycoprotein expression plasmid and $3 \mu \mathrm{g}$ of pNL4-3-Luc-R--E- were used to transfect $293 \mathrm{~T}$ cells (90\% confluent) in 6-well plates with polyethylenimine (PEI). The DNA cocktail was added to $200 \mu \mathrm{l}$ Opti-MEM media and PEI was added at $2 \times$ the volume of DNA. The mixture was incubated at room temperature for $15 \mathrm{~min}$. 293T producer cells were rinsed with PBS (no $\mathrm{Ca}^{++} / \mathrm{no} \mathrm{Mg}^{++}$). Eight hundred microliters of Opti-MEM was added to each well and the PEI/ DNA mixture was added. After 5-6 h incubation at $37^{\circ} \mathrm{C}$, the DNA cocktail was aspirated off and $3 \mathrm{ml}$ cell culture media was added per well. A minimum of two wells per mutant were done at each time, for a total of $6 \mathrm{ml}$. The supernatants containing the pseudotyped viruses were collected $48 \mathrm{~h}$ posttransfection and filtered through a 0.45 $\mu \mathrm{m}$-pore-size filter (Nalgene).

\section{Pseudotyped virus infectivity assay}

Huh7 or Hep3B cells were seeded in 12-well plates at a density of $8 \times 10^{4}$ per well one day prior to infection. Cells were incubated with $500 \mu \mathrm{l}$ of pseudotyped virus for $6 \mathrm{~h}$, then virus was removed and cell growth media was added. The cells were lysed in $100 \mu \mathrm{l}$ of cell culture lysis reagent (Promega) at $72 \mathrm{~h}$ post-infection (PI). The luciferase activity was measured with a luciferase assay kit (Promega) and a FB12 luminometer (Berthold detection system) according to supplier's protocol. Each sample was done in duplicate and experiments were repeated at least three times.

\section{Western Blot analysis}

To determine HCV E1E2 expression and incorporation, 293 producer cells transfected with HCV E1E2/HIV plas- mids as described above, were lysed in $0.5 \mathrm{ml}$ of $1 \%$ Triton X-100 lysis buffer (50 mM Tris-HCl [pH 7.5], $150 \mathrm{mM}$ $\mathrm{NaCl}, 5 \mathrm{mM}$ EDTA) and protease inhibitor cocktail (10 $\mu \mathrm{g} / \mathrm{ml}$ leupeptin and pepstatin, $5 \mu \mathrm{g} / \mathrm{ml}$ aprotinin and 2 $\mathrm{mM}$ phenylmethylsulfonyl fluoride) after harvesting virus and rinsing cells with PBS (no $\mathrm{Ca}^{++} / \mathrm{no} \mathrm{Mg}^{++}$). The protein samples were spun down at $14 \mathrm{k}$ for $10 \mathrm{~min}$ to clear cellular debris and transferred to fresh eppendorf tubes. SDSPAGE loading dye was added to the protein samples, which were subsequently boiled for $5 \mathrm{~min}$ at $95^{\circ} \mathrm{C}$, followed by sodium dodecyl sulfate-polyacrylamide gel electrophoresis (SDS-PAGE) and transferred to a polyvinyl difluoride membrane (PVDF). Membranes were then probed for HCV glycoproteins E1 and E2 and actin, p24 or GST using peroxidase-conjugated secondary antibody and chemiluminescence reagent according to the supplier's protocol (SuperSignal West pico chemiluminescent substrate, Pierce). To determine incorporation of E1 and E2 into the pseudotyped viruses, $4 \mathrm{ml}$ of pseudotyped virus was layered onto a $1 \mathrm{ml}$ cushion of $20 \%$ sucrose in PBS and centrifuged at 55,000 rpm for $45 \mathrm{~min}$ in a SW55Ti rotor (Beckman Coulter) at $16^{\circ} \mathrm{C}$. The pelleted pseudovirions were lysed in $50 \mu \mathrm{l}$ of $1 \%$ Triton X-100 lysis buffer and subjected to SDS-PAGE and Western Blot analysis.

\section{CD8 I binding assay}

The CD81 clone used was kindly provided by Shoshana Levy, PhD (Stanford University). A glutathione S-transferase (GST) fusion protein containing the large extracellular loop (LEL) of human CD81 was generated as previously described [4]. 293T producer cells were transfected with $1 \mu \mathrm{g}$ HCV E1E2 DNA using PEI. After 48 h cells were lysed in $0.5 \%$ Triton X-100 lysis buffer with protease inhibitor on ice for $30 \mathrm{~min}$. Cell lysates were clarified by centrifuging at $20,000 \times \mathrm{g}$ for $30 \mathrm{~min}$ at $4{ }^{\circ} \mathrm{C}$. Two-hundred microliters of clarified lysates from these cells were incubated with $5 \mu \mathrm{g}$ of CD81-GST fusion protein or GST protein alone with gentle rocking at $4^{\circ} \mathrm{C}$ for $16 \mathrm{~h}$. Fifty microliters of Glutathione Sepharose 4B (GSH) beads (GE Healthcare) rinsed three times with PBS $(140 \mathrm{mM} \mathrm{NaCl}$, $27 \mathrm{mM} \mathrm{KCl}, 10 \mathrm{mM} \mathrm{Na}_{2} \mathrm{HPO}_{4}, 1.8 \mathrm{mM} \mathrm{KH}_{2} \mathrm{PO}_{4}$ ) were added and incubated at $4^{\circ} \mathrm{C}$ for $1 \mathrm{~h}$. The slurry was spun down for $1 \mathrm{~min}$ at $14,000 \mathrm{rpm}$ and GSH beads were rinsed two times with $0.5 \%$ Triton X-100 lysis buffer. SDSPAGE loading dye was added to the beads and samples were boiled at $95^{\circ} \mathrm{C}$ for $5 \mathrm{~min}$. Slurry was spun down again and supernatant was collected for SDS-PAGE and Western Blot analysis.

\section{E2 conformational antibody immunoprecipitation}

293T producer cells were transfected with $1 \mu \mathrm{g}$ wt or a selection of CD81 binding deficient or binding competent mutant HCV E1E2 DNA constructs using PEI. After $48 \mathrm{~h}$ cells were lysed in $0.5 \%$ Triton X-100 lysis buffer with protease inhibitor on ice for $30 \mathrm{~min}$. Cell lysates were clari- 
fied by centrifuging at $20,000 \times \mathrm{g}$ for $30 \mathrm{~min}$ at $4^{\circ} \mathrm{C}$. Fourhundred microliters of clarified lysates from these cells were incubated with $1 \mu \mathrm{g}$ of AR3A conformational antibody [45] with gentle rocking at $4{ }^{\circ} \mathrm{C}$ for $16 \mathrm{~h}$. Immobilized protein A (Pierce) beads were rinsed three times with PBS $\left(140 \mathrm{mM} \mathrm{NaCl}, 27 \mathrm{mM} \mathrm{KCl}, 10 \mathrm{mM} \mathrm{Na} \mathrm{HPO}_{4}, 1.8\right.$ $\mathrm{mM} \mathrm{KH_{2 }} \mathrm{PO}_{4}$ ). Fifty microliters of rinsed polyA beads were then added to the cell lysate/antibody cocktail and incubated with gentle rocking at $4{ }^{\circ} \mathrm{C}$ for $2 \mathrm{~h}$. Beads were washed three times with $100 \mu \mathrm{l} 0.5 \%$ Triton lysis buffer. SDS-PAGE loading dye was added to the beads and samples were boiled at $95^{\circ} \mathrm{C}$ for $5 \mathrm{~min}$. Slurry was spun down and supernatant was collected for SDS-PAGE separation and Western Blot analysis with a polyclonal anti E2 antibody (Virostat).

\section{EIE2 association pull-down}

293T producer cells were transfected with $1 \mu \mathrm{g}$ HCV E1E2 expression plasmid using PEI. Forty-eight h post-transfection cells were lysed in 4\% Triton X-100 lysis buffer (4\% Triton X-100, $100 \mathrm{mM}$ Tris HCl [pH 8.0], 1 mM EDTA) [56] with protease inhibitor for $30 \mathrm{~min}$ on ice. Cell lysates were clarified by centrifuging at $20,000 \times \mathrm{g}$ for $30 \mathrm{~min}$ at $4{ }^{\circ} \mathrm{C}$. Five-hundred microliters of cell lysate was incubated with $5 \mu \mathrm{g}$ ViroStat polyclonal, goat anti-E2 antibody for $16 \mathrm{~h}$ at $4^{\circ} \mathrm{C}$ with gentle rocking. Immobilized protein $\mathrm{A}$ (Pierce) beads were rinsed three times with PBS $(140 \mathrm{mM}$ $\mathrm{NaCl}, 27 \mathrm{mM} \mathrm{KCl}, 10 \mathrm{mM} \mathrm{Na}_{2} \mathrm{HPO}_{4}, 1.8 \mathrm{mM} \mathrm{KH}_{2} \mathrm{PO}_{4}$ ). Fifty microliters polyA beads were then added to the cell lysate/antibody cocktail and incubated with gentle rocking at $4{ }^{\circ} \mathrm{C}$ for $2 \mathrm{~h}$. Beads were washed four times with 100 $\mu \mathrm{l}$ PBS with $0.2 \%$ Triton. SDS-PAGE loading dye was added to the beads and samples were boiled at $95^{\circ} \mathrm{C}$ for 5 min. Slurry was spun down and supernatant was collected for SDS-PAGE separation and Western Blot analysis with anti E1 antibody (Virostat).

\section{Authors' contributions}

KBR participated in the design of the study, performed the experiments and drafted the manuscript. BM set up HIV pseudotyping system. SU participated in designing experiments and drafted the manuscript. LR designed the study and participated in drafting the manuscript.

\section{Acknowledgements}

We thank Charlie Rice, Shoshana Levy, Steve Foung, Michael Lai and Dennis Burton for reagents. The laboratory research was supported by National Institutes of Health grants AI 048056 and Al 059570. L.R. was a recipient of the Schweppe Foundation Career Development Award.

\section{References}

I. Lindenbach BD, Rice CM: Flaviviridae: The viruses and their replication. In Field's Virology Volume 2. 4th edition. Edited by: Knipe DM and Howley PM. Philadelphia, Pippincott Williams \& Wilkins; 2001:991-1041.

2. Lavie M, Goffard A, Dubuisson J: Assembly of a functional HCV glycoprotein heterodimer. Curr Issues Mol Biol 2007, 9:7I-86.
3. Pileri P, Uematsu Y, Campagnoli S, Galli G, Falugi F, Petracca R, Weiner AJ, Houghton M, Rosa D, Grandi G, Abrignani S: Binding of hepatitis C virus to CD8I. Science 1998, 282:938-94I.

4. Meola A, Sbardellati A, Bruni Ercole B, Cerretani M, Pezzanera M, Ceccacci A, Vitelli A, Levy S, Nicosia A, Traboni C, McKeating J, Scarselli E: Binding of hepatitis C virus E2 glycoprotein to CD8I does not correlate with species permissiveness to infection. J Virol 2000, 74:5933-5938.

5. Flint M, von Hahn T, Zhang J, Farquhar M, Jones CT, Balfe P, Rice CM, McKeating JA: Diverse CD8 I proteins support hepatitis $C$ virus infection. J Virol 2006, 80: I I33I-I I342.

6. Cormier EG, Tsamis F, Kajumo F, Durso RJ, Gardner JP, Dragic T: CD8I is an entry coreceptor for hepatitis C virus. Proc Natl Acad Sci U S A 2004, 101:7270-7274.

7. Scarselli E, Ansuini H, Cerino R, Roccasecca RM, Acali S, Filocamo G, Traboni $C$, Nicosia A, Cortese R, Vitelli A: The human scavenger receptor class $B$ type $I$ is a novel candidate receptor for the hepatitis C virus. Embo J 2002, $21: 5017-5025$.

8. Maillard P, Huby T, Andreo U, Moreau M, Chapman J, Budkowska A: The interaction of natural hepatitis $C$ virus with human scavenger receptor SR-BI/Cla I is mediated by ApoB-containing lipoproteins. Faseb J 2006, 20:735-737.

9. Voisset C, Callens N, Blanchard E, Op De Beeck A, Dubuisson J, Vu$\mathrm{Dac} N$ : High density lipoproteins facilitate hepatitis $C$ virus entry through the scavenger receptor class B type I. J Biol Chem 2005, 280:7793-7799.

10. Agnello V, Abel G, Elfahal M, Knight GB, Zhang QX: Hepatitis C virus and other flaviviridae viruses enter cells via low density lipoprotein receptor. Proc Natl Acad Sci U S A 1999, 96: 12766-I277I.

II. Monazahian M, Bohme I, Bonk S, Koch A, Scholz C, Grethe S, Thomssen R: Low density lipoprotein receptor as a candidate receptor for hepatitis C virus. J Med Virol 1999, 57:223-229.

12. Evans MJ, von Hahn T, Tscherne DM, Syder AJ, Panis M, Wolk B, Hatziioannou T, McKeating JA, Bieniasz PD, Rice CM: Claudin-I is a hepatitis $C$ virus co-receptor required for a late step in entry. Nature 2007, 446:80I-805.

13. Zheng A, Yuan F, Li Y, Zhu F, Hou P, Li J, Song X, Ding M, Deng H: Claudin- 6 and claudin-9 function as additional coreceptors for hepatitis C virus. J Virol 2007, 81 : I2465-1247I.

14. Mee CJ, Grove J, Harris HJ, Hu K, Balfe P, McKeating JA: Effect of cell polarization on hepatitis C virus viral entry. J Virol 2007.

15. Pohlmann S, Zhang J, Baribaud F, Chen Z, Leslie GJ, Lin G, GranelliPiperno A, Doms RW, Rice CM, McKeating JA: Hepatitis C virus glycoproteins interact with DC-SIGN and DC-SIGNR. J Virol 2003, 77:4070-4080.

16. Barth H, Ulsenheimer A, Pape GR, Diepolder HM, Hoffmann M, Neumann-Haefelin C, Thimme R, Henneke P, Klein R, Paranhos-Baccala G, Depla E, Liang TJ, Blum HE, Baumert TF: Uptake and presentation of hepatitis $\mathrm{C}$ virus-like particles by human dendritic cells. Blood 2005, 105:3605-36I4.

17. van Kooyk Y, Geijtenbeek TB: DC-SIGN: escape mechanism for pathogens. Nat Rev Immunol 2003, 3:697-709.

18. Cormier EG, Durso RJ, Tsamis F, Boussemart L, Manix C, Olson WC, Gardner JP, Dragic T: L-SIGN (CD209L) and DC-SIGN (CD209) mediate transinfection of liver cells by hepatitis $C$ virus. Proc Natl Acad Sci U S A 2004, I0 I: I 4067- 14072.

19. Lozach PY, Amara A, Bartosch B, Virelizier JL, Arenzana-Seisdedos F, Cosset FL, Altmeyer R: C-type lectins L-SIGN and DC-SIGN capture and transmit infectious hepatitis $C$ virus pseudotype particles. J Biol Chem 2004, 279:32035-32045.

20. Rigotti $A$, Miettinen HE, Krieger M: The role of the high-density lipoprotein receptor SR-BI in the lipid metabolism of endocrine and other tissues. Endocr Rev 2003, 24:357-387.

21. Kapadia SB, Barth H, Baumert T, McKeating JA, Chisari FV: Initiation of hepatitis $C$ virus infection is dependent on cholesterol and cooperativity between CD8I and scavenger receptor B type I. J Virol 2007, 8I:374-383.

22. Bartosch B, Vitelli A, Granier C, Goujon C, Dubuisson J, Pascale S, Scarselli E, Cortese R, Nicosia A, Cosset FL: Cell entry of hepatitis $C$ virus requires a set of co-receptors that include the CD8I tetraspanin and the SR-BI scavenger receptor. J Biol Chem 2003, 278:4I624-4I630.

23. Heo TH, Lee SM, Bartosch B, Cosset FL, Kang CY: Hepatitis C virus E2 links soluble human CD8I and SR-B I protein. Virus Res 2006, I 21:58-64. 
24. Levy S, Todd SC, Maecker HT: CD8I (TAPA-I): a molecule involved in signal transduction and cell adhesion in the immune system. Annu Rev Immunol 1998, 16:89-109.

25. Drummer HE, Wilson KA, Poumbourios P: Determinants of CD8 I dimerization and interaction with hepatitis $C$ virus glycoprotein E2. Biochem Biophys Res Commun 2005, 328:25I-257.

26. Kitadokoro K, Bordo D, Galli G, Petracca R, Falugi F, Abrignani S, Grandi G, Bolognesi M: CD8I extracellular domain 3D structure: insight into the tetraspanin superfamily structura motifs. Embo J 200I, 20:12-18.

27. Martin F, Roth DM, Jans DA, Pouton CW, Partridge LJ, Monk PN, Moseley GW: Tetraspanins in viral infections: a fundamental role in viral biology? J Virol 2005, 79:10839-1085।.

28. Hemler ME: Tetraspanin functions and associated microdomains. Nat Rev Mol Cell Biol 2005, 6:80I-8II.

29. Lindenbach BD, Evans MJ, Syder AJ, Wolk B, Tellinghuisen TL, Liu CC, Maruyama T, Hynes RO, Burton DR, McKeating JA, Rice CM: Complete replication of hepatitis $\mathbf{C}$ virus in cell culture. Science 2005, 309:623-626.

30. Wakita T, Pietschmann T, Kato T, Date T, Miyamoto M, Zhao Z Murthy K, Habermann A, Krausslich HG, Mizokami M, Bartenschlager $\mathrm{R}$, Liang TJ: Production of infectious hepatitis $\mathbf{C}$ virus in tissue culture from a cloned viral genome. Nat Med 2005, II:791-796.

31. Zhong J, Gastaminza P, Cheng G, Kapadia S, Kato T, Burton DR, Wieland SF, Uprichard SL, Wakita T, Chisari FV: Robust hepatitis C virus infection in vitro. Proc Natl Acad Sci U S A 2005, 102:9294-9299.

32. Lindenbach BD, Meuleman P, Ploss A, Vanwolleghem T, Syder AJ, McKeating JA, Lanford RE, Feinstone SM, Major ME, Leroux-Roels G, Rice CM: Cell culture-grown hepatitis $C$ virus is infectious in vivo and can be recultured in vitro. Proc Natl Acad Sci U S A 2006 103:3805-3809.

33. Higginbottom A, Quinn ER, Kuo CC, Flint M, Wilson LH, Bianchi E, Nicosia A, Monk PN, McKeating JA, Levy S: Identification of amino acid residues in CD8 I critical for interaction with hepatitis C virus envelope glycoprotein E2. J Virol 2000, 74:3642-3649.

34. Petracca R, Falugi F, Galli G, Norais N, Rosa D, Campagnoli S, Burgio V, Di Stasio E, Giardina B, Houghton M, Abrignani S, Grandi G: Structure-function analysis of hepatitis $C$ virus envelope-CD8 I binding. J Virol 2000, 74:4824-4830.

35. Yagnik AT, Lahm A, Meola A, Roccasecca RM, Ercole BB, Nicosia A, Tramontano A: A model for the hepatitis $C$ virus envelope glycoprotein E2. Proteins 2000, 40:355-366.

36. Roccasecca R, Ansuini H, Vitelli A, Meola A, Scarselli E, Acali S, Pezzanera M, Ercole BB, McKeating J, Yagnik A, Lahm A, Tramontano A Cortese R, Nicosia $A$ : Binding of the hepatitis $C$ virus E2 glycoprotein to CD8I is strain specific and is modulated by a complex interplay between hypervariable regions I and 2. J Viro 2003, 77: 1856-1867.

37. Owsianka A, Clayton RF, Loomis-Price LD, McKeating JA, Patel AH Functional analysis of hepatitis $C$ virus E2 glycoproteins and virus-like particles reveals structural dissimilarities between different forms of E2. J Gen Virol 200I, 82:1877-I883.

38. Clayton RF, Owsianka A, Aitken J, Graham S, Bhella D, Patel AH: Analysis of antigenicity and topology of E2 glycoprotein present on recombinant hepatitis $\mathbf{C}$ virus-like particles. J Virol 2002, 76:7672-7682.

39. Flint M, Thomas JM, Maidens CM, Shotton C, Levy S, Barclay WS, McKeating JA: Functional analysis of cell surface-expressed hepatitis C virus E2 glycoprotein. J Virol 1999, 73:6782-6790.

40. Diedrich G: How does hepatitis C virus enter cells? Febs J 2006, 273:387|-3885.

4I. Christie JM, Chapel H, Chapman RW, Rosenberg WM: Immune selection and genetic sequence variation in core and envelope regions of hepatitis C virus. Hepatology 1999, 30:1037-1044

42. Rai $T$, Caffrey $M$, Rong $L$ : Identification of two residues within the LDL-A module of Tva that dictate the altered receptor specificity of mutant subgroup A avian sarcoma and leukosis viruses. I Virol 2005, 79: | 4962-14966.

43. Goffard A, Callens N, Bartosch B, Wychowski C, Cosset FL, Montpellier $C$. Dubuisson J: Role of $\mathbf{N}$-linked glycans in the functions of hepatitis C virus envelope glycoproteins. J Virol 2005, 79:8400-8409.
44. Dubuisson J: Folding, assembly and subcellular localization of hepatitis C virus glycoproteins. Curr Top Microbiol Immunol 2000, 242: 135- I 48 .

45. Law M, Maruyama T, Lewis J, Giang E, Tarr AW, Stamataki Z, Gastaminza P, Chisari FV, Jones IM, Fox RI, Ball JK, McKeating JA, Kneteman NM, Burton DR: Broadly neutralizing antibodies protect against hepatitis $\mathbf{C}$ virus quasispecies challenge. Nat Med 2008, 14:25-27.

46. Cocquerel L, Meunier JC, Pillez A, Wychowski C, Dubuisson J: A retention signal necessary and sufficient for endoplasmic reticulum localization maps to the transmembrane domain of hepatitis C virus glycoprotein E2. J Virol I998, 72:2 |83-2I9|.

47. Op De Beeck A, Voisset C, Bartosch B, Ciczora Y, Cocquerel L, Keck Z, Foung S, Cosset FL, Dubuisson J: Characterization of functional hepatitis C virus envelope glycoproteins. J Virol 2004, 78:2994-3002.

48. Drummer HE, Poumbourios P: Hepatitis C virus glycoprotein E2 contains a membrane-proximal heptad repeat sequence that is essential for EIE2 glycoprotein heterodimerization and viral entry. I Biol Chem 2004, 279:30066-30072.

49. Sandrin V, Boulanger P, Penin F, Granier C, Cosset FL, Bartosch B: Assembly of functional hepatitis $C$ virus glycoproteins on infectious pseudoparticles occurs intracellularly and requires concomitant incorporation of EI and E2 glycoproteins. J Gen Virol 2005, 86:3189-3199.

50. Ciczora Y, Callens N, Montpellier C, Bartosch B, Cosset FL, Op de Beeck $A$, Dubuisson J: Contribution of the charged residues of hepatitis C virus glycoprotein E2 transmembrane domain to the functions of the EIE2 heterodimer. I Gen Virol 2005, 86:2793-2798.

51. Ciczora Y, Callens N, Penin F, Pecheur El, Dubuisson J: Transmembrane domains of hepatitis $C$ virus envelope glycoproteins: residues involved in EIE2 heterodimerization and involvement of these domains in virus entry. I Virol 2007 8I:2372-238I.

52. Yi M, Nakamoto Y, Kaneko S, Yamashita T, Murakami S: Delineation of regions important for heteromeric association of hepatitis C virus EI and E2. Virology 1997, 23 1: I 19-129.

53. Cocquerel L, Meunier JC, Op de Beeck A, Bonte D, Wychowski C, Dubuisson J: Coexpression of hepatitis $C$ virus envelope proteins EI and E2 in cis improves the stability of membrane insertion of E2. J Gen Virol 200I, 82:1629-1635.

54. Owsianka AM, Timms JM, Tarr AW, Brown RJ, Hickling TP, Szwejk A, Bienkowska-Szewczyk K, Thomson BJ, Patel AH, Ball JK: Identification of conserved residues in the E2 envelope glycoprotein of the hepatitis $C$ virus that are critical for CD8I binding. J Virol 2006, 80:8695-8704

55. Lavillette D, Pecheur El, Donot P, Fresquet J, Molle J, Corbau R, Dreux M, Penin F, Cosset FL: Characterization of fusion determinants points to the involvement of three discrete regions of both EI and E2 glycoproteins in the membrane fusion process of hepatitis C virus. J Virol 2007, 81:8752-8765.

56. Cocquerel L, Quinn ER, Flint M, Hadlock KG, Foung SK, Levy S: Recognition of native hepatitis C virus EIE2 heterodimers by a human monoclonal antibody. J Virol 2003, 77:1604-1609.

Publish with Bio Med Central and every scientist can read your work free of charge

"BioMed Central will be the most significant development for disseminating the results of biomedical research in our lifetime. "

Sir Paul Nurse, Cancer Research UK

Your research papers will be:

- available free of charge to the entire biomedical community

- peer reviewed and published immediately upon acceptance

- cited in PubMed and archived on PubMed Central

- yours - you keep the copyright 